\title{
Integration of Non-Technical Engineering Competences into Contemporary Engineering Curricula
}

\author{
http://dx.doi.org/10.3991/ijep.v3i2.2405 \\ T. Rüütmann, V. Parts, M. Teichmann and H. Kipper \\ Tallinn University of Technology, Tallinn, Estonia
}

\begin{abstract}
Today the professional competence of an engineer has become crucial for further social and economic developments. Importance of implementing non-technical engineering competencies in general education of engineers for forming their personality has been discussed in the present paper.
\end{abstract}

Index Terms-Engineering curriculum, engineering education, model of non-technical engineering competences, nontechnical engineering competences.

\section{INTRODUCTION}

Nowadays we often hear talk about educative innovation as a locomotive of change. Engineering education today provides high-level engineering competences. Unfortunately, we often hear that non-technical and technical engineering competences follow different paths that their ways not only do not intersect, but are totally divergent. Still, an integral education requires them to be integrated, making their borders permeable and bringing them closer to one another, redounding to all society.

The present educational structure often divorces technical and non-technical engineering competences starting in the early educational stages, leading up to the university level. Once at the university level, things get even worse: technical education excludes non-technical aspects and vice versa. The two appear insoluble, like a mix of oil and vinegar; sometimes they achieve a timid coexistence in some pre-university studies, which does not resolve the problem. Society is not exempt from responsibility. People are impelled towards super-specialization and the idea of wasting time by devoting themselves to nontechnical subjects is widespread. We live immersed in a world whose main message is the importance of gaining material success.

The importance of implementing non-technical engineering competences in the general education of engineers in order to form their personality has been emphasized in several documents compiled by leading international engineering organizations.

The European Federation of National Engineering Associations (FEANI) in its "Codes of Conduct" [1] has defined ethics of personality, professional ethics, and the social responsibility of engineers. The Codes of Conduct require that engineers must have the ability to perform their profession in accordance with rules of good practice and proper behavior. Engineers must have a responsibility to nature, their life environment, safety and health, and keeping the traditional cultural values of the country. This Pan-European statement on engineering ethics and conduct is implemented through the codes issued by national engineering associations. These codes can, and in general already do, incorporate the listed objectives in a form which reflects national circumstances and allows additional objectives to be added as required by national practice.

The Accreditation Board for Engineering and Technology in the U.S.A. (ABET) requires, according to its Criteria 2010-2011 [2] and Criteria 2012-2013 [3] for Accrediting Engineering Programs, that graduates from engineering programs must have the ability to conduct experiments and to design systems, components or processes, but also to have an understanding of professional and ethical responsibility, to be able to communicate effectively, to have a broad education necessary for understanding the impact of engineering solutions in a global/societal context, etc.

The Institute of Electrical and Electronic Engineers (IEEE), the world's largest professional association of engineers, has accepted the "Code of Ethics" [4] to stimulate ethical imagination, learn ethical requirements, analyze ethical concepts, etc.

The American Society for Engineering Education (ASEE) has launched its curricula plan "General Education in Engineering" [5] for social studies, anticipating close cooperation between faculties of engineering and liberal arts, developing a designated sequence of courses extended throughout general studies.

The International Society for Engineering Education (IGIP) has declared one of its missions to be integrating technical and non-technical engineering skills in engineering curricula. The IGIP has founded the International Working Group "Language and Humanities in Engineering Education" with the aim of integrating non-technical and technical engineering competences into contemporary engineering curricula [6].

The European Society of Engineering Education (SEFI), being a network of institutions of higher engineering education, individuals, associations and companies in Europe, has founded a working group "Ethics in Engineering Education" [7]. Members of SEFI declare that issues of sustainable development, globalization and poverty reduction have led to much discussion on the changing role of the engineer and, subsequently, engineering education. There is increasing international acknowledgement of the need for a global dimension in engineering education to address current and future economic, 
social and environmental challenges. Associated with this are the skills and knowledge needed for ethical decisionmaking and action. An understanding of ethics and ethical responsibilities provides grounding for the global engineer that supports activities ranging from day-to-day work issues to international policy-making.

The documents mentioned above prescribe professional engineering competences, emphasizing that contemporary requirements for engineers have not been restricted to their professional technical functions only the integration of non-technical and technical engineering competences is expected. In addition to engineering (including STEM - science, technology, engineering, mathematics) competences, societal, ethical, legislative, regulatory, and commercial issues should also be taken into account in curriculum design.

The present paper will discuss the objectives of providing non-technical competences in general engineering education.

\section{IMPORTANCE OF NON-TECHNICAL ENGINEERING COMPETENCES IN ENGINEERING EDUCATION}

A necessary component in preparing for the professional world is a general engineering education that complements the technical content of the curriculum and is consistent with the program and institution objectives. The curriculum preparing students for engineering practice should include more considerations in economics, environmental sustainability, manufacturability, ethical, legislative, health and safety issues, and other social sciences (incl. work and organizational psychology).

Although some members of the teaching staff of technical universities sometimes underestimate the nontechnical competences of engineers, these courses have a vital position in engineering curricula. According to $\mathrm{R}$. Ruprecht [8], humanities and non-technical engineering competences are very special and precious in an engineering curriculum, as they alone constantly reach beyond their own limits. Their goal is the deepening of students' insight into a field they either believe to be beyond their understanding or are familiar enough with and feel they do not need to deal with it any longer. Students are confronted with an alternative process of thinking in disciplines such as philosophy, psychology, sociology, ethics, pedagogy, etc., but they also get acquainted with the terminology, methodology, general rules, concepts, and important personalities that have a significant influence on the development of these sciences.

Non-technical engineering competences afford an approach to problems that is fundamentally different compared to technical engineering competences. Being confronted with social sciences on a tertiary level is different from the same confrontation on a primary and secondary level. There, factual knowledge and analyzing and reasoning skills are in the focus of teaching and learning. On a tertiary level, insight should be the goal. It is most important that students become aware of a broader perspective, thus acquiring some respect for different approaches to our existence and values.

Engineers are of the position that subjects related to social sciences that afford non-technical engineering competences do not bring immediate usable knowledge and skills. D. Dobrovská [9] proves that technical universities more willingly include supplementary courses in their engineering curricula if they have a practical link to technical courses, or their personality - usually thing like rhetoric, applied social psychology, and foreign languages. Their contribution is not immediately perceivable and measurable although their presence in offered curricula is important.

According to W. Ravesteijn et al [10], the definition of the competencies that engineers should possess is usually based on an implicit model of the engineer as a rational actor. This model, however, does no justice to the social nature of technology development and it does not take into account the natural variety in social acting. W. Ravesteijn and his colleagues have formulated three types of competences necessary for engineering graduates: an instrumental competence, a strategic competence, and a communicative competence.

Engineering students receive their instrumental competence in their technical education. Their education also comprises lessons in the field of strategic competences, while schools for management and policy provide a full education of the knowledge and capabilities implied by strategic competence. Elements of the communicative competence are also being taught, however, to date most of them are not taught in a systematic way. Projects integrating traditional engineering knowledge and skills, including strategic ones, on the one hand and communicative abilities on the other provide both the opportunity to learn about these topics and the chance to learn to work in a team.

\section{A. The Importance of Teaching Quality}

Engineering educators play a crucial role in supporting the learning experience of young engineers. They are the key players in engineering education systems and in the implementation of reforms that could develop a highperformance, knowledge-driven economy. They contribute to the high quality of engineering education, providing engineers with good personal qualities, better social skills, and wider employment opportunities.

The IGIP [6] founded in 1972, has stated its mission to be:

- Improving teaching methods in technical subjects;

- Developing practice-oriented curricula that correspond to the needs of students and employers;

- Encouraging the use of media in technical teaching;

- Integrating languages and the humanities into engineering education;

- Fostering management training for engineers;

- Promoting environmental awareness.

The IGIP has listed contemporary non-technical competences for engineering educators with the aim of improving the quality of teaching in engineering:

- Pedagogical and psychological competencies effective teaching competences, evaluation competences;

- Development and management competencies leadership, management, administrative, educational and legal system;

- Social and communication competences interpersonal competences;

- Ethical and intercultural competencies - professional ethics competences. 
The profession of engineering educators is underestimated. It is crucial to recognize that although engineering educators play a critical role in society, they cannot act alone, as their education and training needs to be of high quality and supported by coherent national or regional policies. The competences of engineering educators have been elaborated by the IGIP in order to improve the quality of engineering education [11].

The IGIP has elaborated a curriculum that provides the minimum qualification profile for engineering educators, teachers and trainers in engineering education in the minimum amount of 20 ECTS, including the following modules [6]:

- Theoretical and practical engineering pedagogy;

- Laboratory didactics and methodology;

- Psychology;

- Sociology;

- Ethics and intercultural competencies;

- Oral communication skills and scientific writing;

- Working with projects;

- Media, e-learning, and computer aided technologies.

The above-listed modules of the IGIP curriculum express contemporary expectations for engineering professors teaching subjects that provide technical engineering competences. It is assumed that they have acquired technical engineering competences in the field of engineering on a high level, having met the competences of an engineer as defined by FEANI [12].

According to the research of D. Dobrovská [9], many professors of technical courses reflect ethical, philosophical, ecological, educational and psychological aspects in the teaching of future engineers and also in their own professional activities, some of them displaying remarkable knowledge of social sciences. The older generation of technical intelligentsia gained their education in social sciences during studies at secondary schools or in their further education.

There are also similar expectations for teachers and professors teaching subjects that provide non-technical engineering competences. These professors must be aware that they teach in a context particularly foreign to them in an engineering environment they have only minimal knowledge of, if any at all. Here they become learners themselves. Nobody wants them to become engineers, but they should appreciate the environment they teach in, thus gradually understanding where they stand while also learning a lot from their students. Professors should convince their students that in the "long-run" during their studies while acquiring non-technical engineering competences, in order to carefully contemplate fundamental concepts and categories and projecting them in a particular, reality is important.

\section{NON-TECHNICAL ENGINEERING COMPETENCES IN ENGINEERING CURRICULA TODAY}

The teaching of non-technical competences at Tallinn University of Technology (TUT) has dramatically changed after the democratic changes in Estonia at the beginning of 1990s. Before that the content and extent of subjects providing non-technical competences, more exactly of political sciences was compulsory, strictly defined, and unified, being incorporated into the whole study period of 5 years.
Since the last decade of the 20th century, the content and extent of non-technical studies have been regulated by the Curricula Statutes of TUT.

The teaching of economics at TUT has a long tradition. Nowadays, specialized study programs in management are organized and economics courses are included in engineering study programs.

Analysis of engineering curricula has been carried out regarding the integration of non-technical subjects into the engineering curricula of TUT.

According to the Curricula Statute of TUT, all engineering curricula should include the following nontechnical subjects with the assigned minimum ECTS (European Credit Transfer System) credits:

- Philosophy 3 ECTS;

- Law 4 ECTS;

- Sustainable development 4 ECTS;

- Economics and entrepreneurship module 8 ECTS;

- Foreign language 6 ECTS;

- Science of risk and safety 4 ECTS;

- Free electives 12-18 ECTS.

Doctoral curricula of TUT must include the following courses (in minimal amount of 4 ECTS):

- Philosophy of Science;

- Didactics in Higher Engineering education;

- Managerial Psychology (including teamwork, collaboration, conflict management etc).

Several departments of the Faculty of Social Sciences offer non-technical free electives. The following electives are offered for Bachelor and Master Curricula in the Department of Industrial Psychology (to mention but a few):

- Organizational Psychology (including communication) 4 ECTS;

- Communicational Psychology 4 ECTS;

- Ethics of Engineering Proffession 2 ECTS;

- Rhetoric and Debating 5 ECTS;

- Self-Management 2 ECTS.

The Estonian Centre for Engineering Pedagogy offers the following subjects for technical teachers but also for engineering students (to mention but a few):

- Engineering Pedagogy and Didactics of Teaching Engineering 7 ECTS;

- Laboratory Didactics and Methodology 3 ECTS;

- Educational Psychology and Sociology 3 ECTS;

- Ethics and Multicultural Learning Environment 3 ECTS;

- Rhetoric and Scientific Writing 3 ECTS;

- Working with Projects: Curricula Design 3 ECTS;

- Teaching Technology, Media and E-Learning 3 ECTS;

- Didactics of Teaching Engineering 3 ECTS;

- Development of Educational Ideas 3 ECTS.

The engineering curricula of all the engineering faculties of TUT have been analysed. In addition to the nontechnical subjects required by the Curricula Statutes of 
TUT, the following compulsory non-technical subjects were taught in the engineering curricula of TUT:

- Faculty of Mechanical Engineering - Social Anthropology (3 ECTS), Revision of Productive Skills in the Estonian Language (3 ECTS);

- Faculty of Chemical and Materials Technology Ethics of Engineering Profession (2 ECTS), Sociology (3 ECTS), Revision of Productive Skills in the Estonian Language (3 ECTS), Social Skills and Ethics (4 ECTS), Science Communication (3 ECTS);

- Faculty of Civil Engineering - Organizational Behaviour (4 ECTS), Revision of Productive Skills in the Estonian Language (3 ECTS), Visual Communication (2 ECTS), Business Ethics (3 ECTS);

- Faculty of Power Engineering - Communicational Psychology (4 ECTS), Revision of Productive Skills in the Estonian Language (3 ECTS);

- Faculty of Information and Communication Technology (ICT) - Human Communication (3 ECTS), Rhetoric (3 ECTS), Scientific Writing (3 ECTS), Giving Presentations in English (3 ECTS), Speech analysis and Synthesis (3 ECTS), Estonian Language and Culture (3 ECTS), Semantics and Analytical Philosophy (6 ECTS).

According to the presented results of the analysis, it may be concluded that the engineering curricula of ICT faculties have the widest range of compulsory nontechnical subjects (7 subjects, 24 ECTS in total) in addition to the ones required by the Curricula Statute of TUT.

The Faculty of Chemical and Materials Technology provides an additional 5 compulsory non-technical subjects (15 ECTS in total), the faculty of Civil Engineering 4 subjects (12 ECTS in total), the faculty of Power Engineering 2 (7 ECTS in total), and the faculty of Mechanical Engineering 2 compulsory non-technical subjects (total amount being 6 ECTS).

In addition to the compulsory non-technical subjects named above, engineering students have the freedom to select free electives adding up to a total of 12-18 ECTS, depending on the curriculum and faculty. It may be said that there could be more elective non-technical subjects in engineering curricula. Unfortunately students are not always able to build a consistent educational package without professional help. Advice from faculty staff and educators are needed for helping the students to choose the free electives. Suggesting the non-technical courses as free elective ones is essential to develop personal, interpersonal, leadership and managerial competences.

But there are still other important aspects of teaching and learning non-technical subjects - for example, forms and methods of studies. It should not be forgotten that engineers should have an understanding of professional and ethical responsibility; they should be able to communicate effectively, etc. Not much attention is given to the question of how to build these qualities. Active methods of teaching should also be used to teach these nontechnical subjects. Simply sitting in lecture rooms listening to excellent lectures cannot fulfill those goals.

It could be seen from the above presented analysis that the teaching of non-technical subjects is quite different in different engineering faculties of TUT. The so-called conservative and historical engineering faculties of TUT - faculties of Mechanical, Civil and Power Engineering spend less time and credits on teaching non-technical subjects and have been concentrating more on technical engineering subjects. At the same time, the most contemporary and rapidly developing faculty of ICT concentrates more courageously on affording non-technical engineering competences to their graduates.

\section{INTEGRATION OF NON-TECHNICAL ENGINEERING COMPETENCES INTO ENGINEERING CURRICULA}

We suggest the concept of "non-technical engineering competences" to describe the broad field of competences relevant to professional work in the engineering domain. They are different from transferable competences as they are context-specific, i.e. applicable in the context of the engineering profession (although in a rather general way i.e. they are not specific to a concrete occupation). The model of non-technical engineering competences presented in Figure 1 has been elaborated as the result of the research carried out at the department of Industrial Psychology at TUT.

As it could be seen in Figure 1, the model of nontechnical engineering competences consists of six different domains:

- Competences of professional ethics;

- Personal competences;

- Interpersonal competences;

- Leadership, management and administrative competences;

- Innovation and entrepreneurial competences;

- Competences of law and the legal system.

Analysis of the engineering curricula of all the engineering faculties of TUT indicates that there are a large number of non-technical subjects (Figure 1). On the other hand, the content of those subjects, and especially subjects' learning outcomes, do not strictly follow the general understanding of non-technical engineering competences. First, most subjects are electives, i.e. if the student does not choose the subject, and then the development of a specific non-technical competence is not achieved. Second, some non-technical engineering competences development cannot be achieved by any engineering student' curriculum, for example, there is no one subject for developing leadership and managerial competences on the undergraduate and postgraduate level.

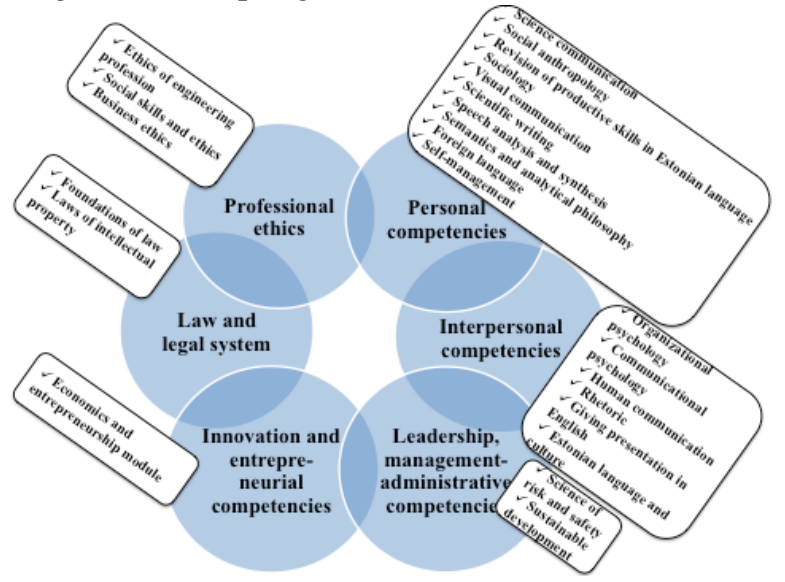

Figure 1. The Model of Non-technical Engineering Competences: Subjects that Develop Non-technical Engineering Competences on Undergraduate and Postgraduate Level 
Law and the legal system is one of the spheres named on the model. Successful engineers should be aware of their rights and responsibilities, legal and social aspects of technology and its usage and possible legal consequences related to their productions. The primary value-added knowledge is related to understanding intellectual property and patent law. Engineers should also understand the legal landscape that they are bound to.

According to Harris et al. [13] and Bower [14], professional ethics should be an essential part in the education of engineers, helping students to deal with ethical issues in their professional practice - providing knowledge of the relationship between science, technology and ethics, and ethical problems of engineers in industry: responsibilities, control, choice, and computing. Engineers' duties in relation to the environment, eco-ethics, and codes of ethics in engineering, as well as the ethical values in different cultures and the relativity of ethical values, are of high importance for future engineers.

Personal competences are the basis that allows an individual to act autonomously, for managing their own lives, and situate their lives in broader social context. Problem solving skills, self-management, life-long learning, career management, etc. promote expected professional behavior and the productivity of engineers.

Interpersonal competences are the basis individuals use when engaging with others, and since they will encounter people from range of backgrounds, it is important that they are able to interact in heterogeneous groups. Skills of cooperation and collaboration, conflict resolution, negotiation are needed for professional conduct in engineering.

Leadership, management and administrative competences provide a foundation for successfully handling certain work situations, managing projects, other tasks, and duties in the professional work of engineers.

Innovation and entrepreneurial competences guarantee the success of engineers, depending on their ability to identify unconventional emerging opportunities using entrepreneurial skills.

The presented architectural model of competences may help engineers and their educators transform the "broad competences”, or the understanding of the wider societal, economical, and environmental context, into qualifications engineers could have. Non-technical competences provided by engineering curricula should be analyzed according to the presented model.

\section{A. Study of Students of the Master Curriculum for Technical Teachers}

In the period of 2010-2012 a study of students and alumni of the Master curriculum for Technical Teachers was carried out at the Estonian Centre for Engineering Pedagogy at TUT.

A special questionnaire consisting of 30 questions was created for the study of students of the Master curriculum for Technical Teachers. The aim of the research was to evaluate the quality of the curriculum and the quality of teaching in order to improve technical teacher education at TUT.

64 students participated in the research, $58 \%$ of them male and $42 \%$ female. All the students participating in the research had acquired academic higher education in different engineering specialties on at least the Master level before attending the Master courses for technical teachers.

Several questions in the questionnaire covered the importance of non-technical subjects in the curriculum. The section on the evaluation of syllabi and subjects in the study included a set of questions regarding whether subjects offer interesting and novel subject matter and upto-date information; whether high quality learning materials are available; the connection of theory with practice; a contemporary learning environment; clear and obtainable learning objectives; the strength of purpose of the subjects and curriculum; consideration of the prior knowledge of learners; the use of contemporary effective teaching methods; e-learning, etc.

Students were asked to answer using a scale of 6 points (from “ 0 - absolutely do not agree” to " 5 - fully agree”).

The subjects of the curriculum and syllabi were evaluated highly, the average score given by the students being 4.25 of the maximum 5. The highest evaluation was given to the subject Engineering Pedagogy Science (4.62 of possible maximum 5). But another set of non-technical subjects was highly appreciated: Educational Psychology and Sociology (4.52), Rhetoric and Scientific Writing (4.51), Product Development and Innovation (4.42), Curriculum Development and Design (4.24), Teaching Technology, Media and E-Learning (4.11), Ethics and Intercultural Relations (4.06), Laboratory Didactics and Methodology (4.03).

It is interesting that subjects providing technical competences received lower ratings from the students than those providing non-technical competences, for example Informatics (average 3.89 from maximum 5) and Standards and Quality (3.94). Still, 90\% of the students were eager to study additional engineering specialty subjects in order to update their knowledge.

Students agreed with the proper structure of the curriculum and the useful syllabi (4.65). Lots of proposals were made (to mention but a few): there could be more psychological and pedagogical subjects included in the curriculum, the list of elective subjects could be longer. The Statute of the curriculum of TUT prescribes the proportion of electives in the curriculum; increasing of the amount of electives could provide students with a wider array of possible selections, including subjects providing nontechnical competences.

As was clearly demonstrated, students are interested in learning non-technical subjects; they would also like to have a wider choice of electives.

We should clarify that we do not intend to flood engineering syllabi and curricula with subjects providing nontechnical competences for engineering students, distorting the contents of either engineering studies or more generally technical careers. The aim is to achieve the objective that engineering students, when joining an enterprise, are aware that the world also has other limits, other dimensions. They should be able to manage also outside of technical environments, be able to strike up a conversation and develop a complete set of dimensions.

\section{CONCLUSIONS}

The professional competence of an engineer has become crucial for further social and economic developments nowadays. Engineering is a diverse profession 
requiring different skills and an engineer has to perform various tasks - technical supervision, personnel management, project development, diagnostics, etc. Moreover, today an engineer must also be capable of intercultural communication in order to work with international partners on joint projects.

For future engineers, it is important to learn how to bridge the gap with the public. They need to be aware of the social consequences of their work as well as of issues of sustainability, safety and ethics. The development of future engineers' communicative competence is a weak spot in the traditional engineering curriculum. There is a possibility to broaden the variety of elective non-technical subjects in engineering curricula.

The non-technical subjects, as a part of engineering education is not sufficiently considered today, even though these could increase employment and career opportunities. The teaching of non-technical subjects should logically be included and development of those competences guaranteed in engineering education. Unfortunately, none of the TUT engineering faculties curricula offer a possibility for the full development of nontechnical engineering competences. Subjects are mainly electives for students, and many of these subjects are integrated into the curriculum for historical reasons and not as a conscious choice for the development of nontechnical engineering competencies. Moreover, the gradual inclusion of certain subjects in different technical curricula should be approached on the basis that such subjects represent an undeniable formative value with the aim of achieving an integral education for engineers. We must be extremely careful when accomplishing such a task, since the risk of excessively increasing the academic load of engineering students could result in either discouragement or low performance.

\section{REFERENCES}

[1] FEANI Position Paper on Code of Conduct: Ethics and Conduct of Professional Engineers (2006) http://www.feani.org/site/index.php ?eID $=t x \_$nawsecuredl $\& u=0 \&$ file=fileadmin/PDF Documents/Posi tion papers/Position Paper Code of Conduct Ethics approved GA_2006.pdf\&t=1353665092\&hash=4ed66dc5def4a6fbb20bab53 ee17e7cc009fa9ac (22.11.2012)

[2] ABET Criteria 2010-2011 for Accrediting Engineering Programs http://www.abet.org/uploadedFiles/Accreditation/Accreditation_Pr ocess/Accreditation Documents/Archive/criteria-eac-20102011.pdf (22.11.2012)

[3] ABET Criteria 2012-2013 for Accrediting Engineering Programs http://www.abet.org/DisplayTemplates/DocsHandbook.aspx?id=3 $\underline{143}(22.11 .2012)$
[4] IEEE Code of Ethics http://www.ieee.org/about/corporate/govern ance/p7-8.html (22.11.2012)

[5] D. F. Ollis, K. A. Neeley, H. C. Luegenbiehl, Liberal Education in Twenty-First Century Engineering, Peter Lang Publishing, 2004.

[6] IGIP http://www.igip.org/igip/ (12.11.2012)

[7] SEFI http://www.sefi.be/?page id=1557 (22.11.2012)

[8] R. Ruprecht, The Contribution of Humanities to the Quality of Engineering Education, in Proceedings of 38the IGIP Symposium - Quality and Quantity of Engineering Education, Graz, Austria, 2009, p 181-184.

[9] D. Dobrovska, J. Mericka, A. Kokorny, Some Problems of the Humanities in Engineering Education. In: Proceedings of $33^{\text {rd }}$ IGIP/IEEE/ASEE Symposium "Local Identity - Global Awareness. Engineering Education Today”, 2004, p 709-713.

[10] W. Ravesteijn, E. de Graaff, O. Kroesen, E. Wiersma The Impact of Communication Skills in Engineering Education, Proceedings of IGIP $35^{\text {th }}$ International Symposium "Engineering Education the Priority for Global Development”, 2006, p 479 - 484.

[11] J. Stakenborg, Competence Development as the Core of Engineering Education, New Trends in Engineering Pedagogy, Prague 2006, $220 \mathrm{p}$.

[12] FEANI http://www.feani.org/site/ (27.11.2012)

[13] Harris, Charles. E.; Pritchard, Michal. S.; Rabins, Michal. J. (2008). Engineering Ethics: Concepts and Cases. 4th Revised edition. Wadsworth Publishing Co Inc, $-336 \mathrm{pp}$.

[14] Bower, W. R. (2009). Engineering Ethics. Outline of an Aspirational Approach. Springer-Verlag London Ltd., - 111 pp.

\section{AUTHORS}

Tiia Rüütmann is an Associate Professor, Head of Estonian Centre for Engineering Pedagogy at Tallinn University of Technology, Ehitajate tee 5, 19086, Tallinn, Estonia (e-mail: tiia.ruutmann@ttu.ee), Member of IGIP EC.

Velli Parts is a Research Fellow at the Department of Industrial Psychology at Tallinn University of Technology, Ehitajate tee 5, 19086, Tallinn, Estonia (e-mail: velli.parts@enop.ee).

Mare Teichmann is a Professor and Head of the Department of Industrial Psychology at Tallinn University of Technology, Ehitajate tee 5, 19086, Estonia (e-mail: mare@pekonsult.ee).

Hants Kipper is a Lecturer at Estonian Centre for Engineering Pedagogy at Tallinn University of Technology, Ehitajate tee 5, 19086, Tallinn, Estonia (e-mail: hants.kipper@ttu.ee ), Member of IGIP IMC.

Received 30 November 2012. Published as resubmitted by the authors 18 March 2013 